\title{
COMPUTATIONAL STUDY ON EFFECT OF MICROWAVE INDUCED HYPERTHERMIA ON BREAST TUMOR
}

\author{
HARJOT SINGH GILL ${ }^{1}$, SHUBHAM KUMAR ${ }^{2}$, SATBIR SINGH SEHGAL ${ }^{\mathbf{3}}$ \& SAJAN SINGH ${ }^{\mathbf{4}}$ \\ Department of Mechanical Engineering, Chandigarh University, Gharuan, Punjab, India
}

\begin{abstract}
In the present research, microwave induced hyperthermia technique was used as a solution, for the treatment of breast tumor of volume $561300 \mathrm{~mm}^{3}$. Techniques like chemotherapy, radiotherapy or surgery are generally used for the treatment of tumor. The present work describes the simulation carried on actual tumor images obtained from MRI scans of the breast. An optimized heat input $(1 \mathrm{~W}-4 \mathrm{~W})$ was selected for constant frequency with respect to transient response Analysis is done on 2D finite element generated pathological human tissue containing tumour. The operating frequency of the antenna is $2.4 \mathrm{GHz}$. Heat is generated using microwave induced hyperthermia and simple methodology of finding effective model parameters for the optimal interstitial microwave hyperthermia treatment is determined.

KEYWORDS: Hyperthermia Technique, Transient Response \& Microwave Hyperthermia Treatment
\end{abstract}

Received: Aug 07, 2017; Accepted: Aug 26, 2017; Published: Oct 12, 2017; Paper Id.: IJMPERDOCT201735

\section{INTRODUCTION}

The term hyperthermia refers to either a phenomenal high fever or the treatment of an infection, by the infusion of an abroad protein utilizing heat. In Hyperthermia temperature of a piece or possibly the entire body raises above the typical degree for a characterized timeframe. The level of temperature, height related to hyperthermia is around a couple of degrees above the ordinary temperature $\left(41-45^{\circ} \mathrm{C}\right)$ (Habash et al. 2006). Hyperthermia used with chemotherapy or radiation therapy elevates the body temperature above the ordinary temperature $\left(41-45^{\circ} \mathrm{C}\right)$ to cause damage to cancer cells [1]. Different types of energy may be used to apply heat, in hyperthermia including microwave, laser, magnetic field and ultrasound [2]. In the Hyperthermia treatment heating of the tumour is always done under controlled conditions. Since, healthy tissue can absorb energy, causing damage with the application of microwave, laser and ultrasound.

\section{Treatment by Hyperthermia}

The best remedial use of heating, that have physiological most essential hyperthermia is the treatment of hurts, agonies, stresses, and sprains by means of use of temperature beneath $41^{\circ} \mathrm{C}$ for 60 minutes or thereabouts and utilize physiological parts of expanding blood flow and metabolic rates (Roemer 1999).

For tumour treatment purposes, there are reports that malignant cellular material is usually more sensitive to temperature than are their normal counterparts

According to a study by American cancer institute 55\% cases of cancer are treated with Surgery, $18 \%$ with chemotherapy, $11 \%$ with radiotherapy and the remaining $16 \%$ using other techniques. 


\section{Techniques used for Hyperthermia Treatment of Cancer}

\section{Magnetic Heating}

The National Cancer Institute classifies hyperthermia into three different methods on which research is being done. They are

- Local hyperthermia

- $\quad$ Regional hyperthermia

- Whole body hyperthermia.

Local hyperthermia is a technique in which a local area such as tumor is treated by using various methods that deliver heat to the infected part. Heat may be applied using different forms of energy which can be radio frequency, ultrasound, and microwave. To treat the tumors just below the skin external approaches are used and to treat the tumors within or near the body cavities Intra luminal or endocavitary methods are used, whereas, tumors deep within the body are treated by interstitial methods.

In regional hyperthermia large area such as body cavity, the organs are heated using deep tissue, regional perfusion and continuous hyper thermic peritoneal perfusion.

And Whole body hyperthermia is treatment of cancer which has spread throughout the body. Since the body can tolerate the temperature rise up to $45^{\circ} \mathrm{C}$, therefore till this temperature is attained normal tissues are not damaged. But some tissue may be affected due to difference in temperature rise at various spots which may cause burns, blisters, pain, discomfort etc. [3-4]

\section{Microwave Hyperthermia}

It is one of the promising techniques which are being used on hundreds of patients, those who are suffering from either breast cancer or prostate cancer. Microwave energy is effective in heating cancerous tumors because tumors have high water content. One or more microwave antenna can be used to treat tumor that depend on tumor size and location in the body. Microwave induced hyperthermia treatment utilizes a single waveguide microwave antenna working at 434,915 and2450MHZ [5-6].

\section{Background of Work Done and Methodology Adopted}

The breast cancer ablation by radiofrequency has been associated with the capacity of concentrating the electromagnetic energy in the tumour area [7]. Radiofrequency ablation in the recent years reached importance for the treatment of cancerous tumor. Breast cancer is believed to have resulted from the interaction of genetic factors, with other environmental factors. The available techniques for breast cancer treatment have strong side effects. The most common used treatment is a mastectomy, an approach which comes down to removing the entire breast and the other is a lumpectomy, in which only the one part of the breast is removed. Other techniques used are such as radiation therapy and chemotherapy that cause the cellular damage all these are ablative techniques. In these treatments the tissue temperature is raised in order to kill the malignant tissue. These types of treatments have a lot of potential, since it can offer a noninvasive treatment with low side effects [8]. In hyperthermia temperature is raised above $42-43^{\circ} \mathrm{C}$ for the sufficient period of time. The challenge of achieving the temperature with non-invasive electromagnetic hyperthermia treatment is to focus 
electromagnetic (EM) power in the cancerous tissue while avoiding the normal tissue. In microwave frequency, energy couples into the tissue through antennas that emits the microwaves [9]. The challenge while working with the microwave ablation is to avoid heating the healthy tissue while heating the tumor. While the relatively high conductivity of tumor tissue increases the local heating potential and thus high temperature difference can be obtained. The hot spots in the healthy tissue areas results in undesired side effects such as burns, blisters and extra pain. More flexible approach, focusing the EM energy is the use of the phase array system. [10].A 2D finite element analysis for the treatment of pathological human tissues containing tumors is presented. The analysis compares the model of coaxial antenna with one, two and three air slots. The model is based on the TM mode coupled with Penne's equation under a transient state condition. The operating frequency of the antenna using is $2.45 \mathrm{GHZ}$ [11]. A zero order mode resonator (ZOR) meta material (MTM) structure for microwave thermotherapy to create and transmit a plane EM wave into treated natural tissue, that can deliver a homogeneous SAR circulation in the plane parallel to tool gap, is generated. ZOR principle is simulated in COMSOL software that shows a very good SAR homogeneity and achieves a penetration depth close to that of EM plane wave [12]. A method of microwave hyperthermia by utilizing thin microwave antenna located in human tissue is described. For the numerical simulation finite element method (FEM) is used.

\section{STRUCTURE OF ANTENNA}

The antenna consists of a thin coaxial cable with a slot measuring $1 \mathrm{~mm}$ cut on the outer conductor $5 \mathrm{~mm}$ for the tip. The antenna is enclosed in a catheter made of poly tetra fluoro ethylene) and operates at the frequency of $2.4 \mathrm{GHz}$, which is used in microwave coagulation therapy [13].

Table 1: Dimension of Coaxial Antenna

\begin{tabular}{|l|c|}
\hline \multicolumn{1}{|c|}{ PROPERTIES } & VALUE \\
\hline Diameter of catheter & $1.79 \mathrm{~mm}$ \\
\hline Diameter of the central conductor & $0.29 \mathrm{~mm}$ \\
\hline Inner diameter of the outer conductor & $0.94 \mathrm{~mm}$ \\
\hline Outer diameter of the outer conductor & $1.79 \mathrm{~mm}$ \\
\hline
\end{tabular}

Table 2: Properties of Material

\begin{tabular}{|c|c|c|}
\hline PROPERTIES & $\begin{array}{c}\text { CONDUCTOR } \\
\text { (Dielectric) }\end{array}$ & CATHETER \\
\hline Relative permittivity & 2.03 & 2.60 \\
\hline
\end{tabular}

\section{REAL IMAGE GEOMETRY MODEL}

In FEM analysis, a correction of the model plays an important role in the simulation. In this paper a set of real image from the MRI sliced was introduced to enhance the breast model design. The actual images help in working on actual volume and size of tumor for better result. The motive is to find out the time in which required temperature can be obtained, which is possible only with the actual volume and size of the tumor. MRI images in axial view, sagittal view and coronal view were imported and rebuild to obtain breast model, with .stl format. This was done with the help of mimics software and through manual segmentation. Later the model is imported into COMSOL multi physics for the simulation.

\section{MODEL SIMULATION}

As described above, the breast model is developed from a set of MRI images and, then the microwave antenna was modelled and inserted into the tumor tissue. The destructive area of the tissue was finally expected to be identified. 
The microwave antenna is kept in the frequency of $2.4 \mathrm{GHz}$. The heat generated from the electric field in the waves is analysed by using COMSOL Multi physics. Modules selected for the simulation are RF module and the bio heat. FEM meshing refinement is done by automatic initial mesh of tetrahedral mesh shape. The physics and all the boundary conditions are assigned to the domains and are shown above in the table 1. Figure 1: Domain represents the breast tissue, whereas the circled domain is the tumor inside the breast model

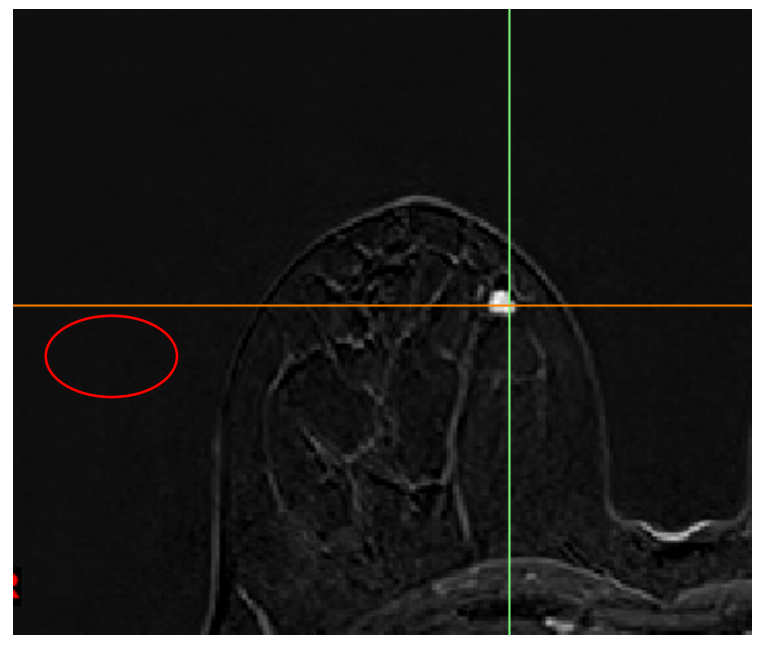

Figure 1: MRI Image of the Cancer Patient

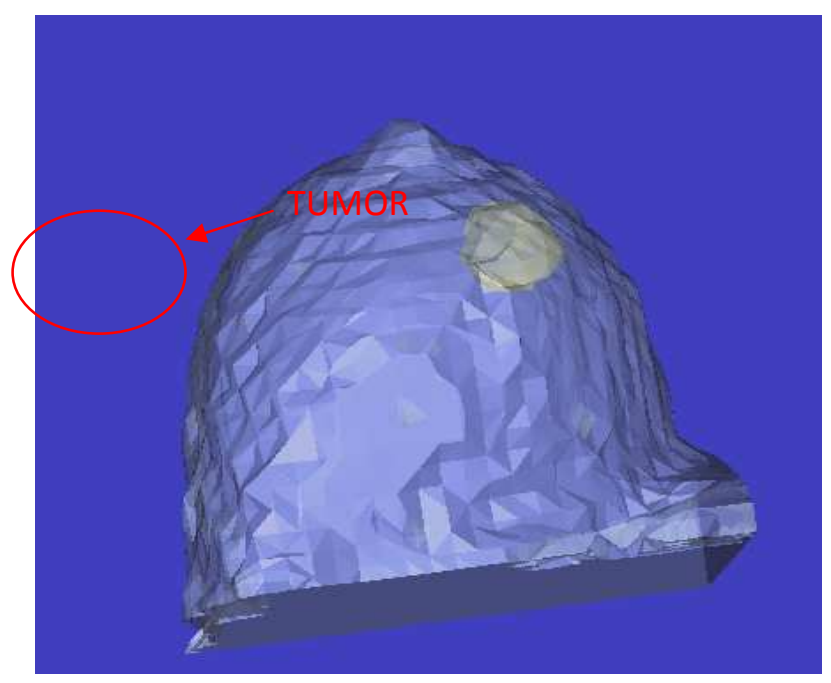

Figure 2: 3D CAD Model of the Cancerous Breast 


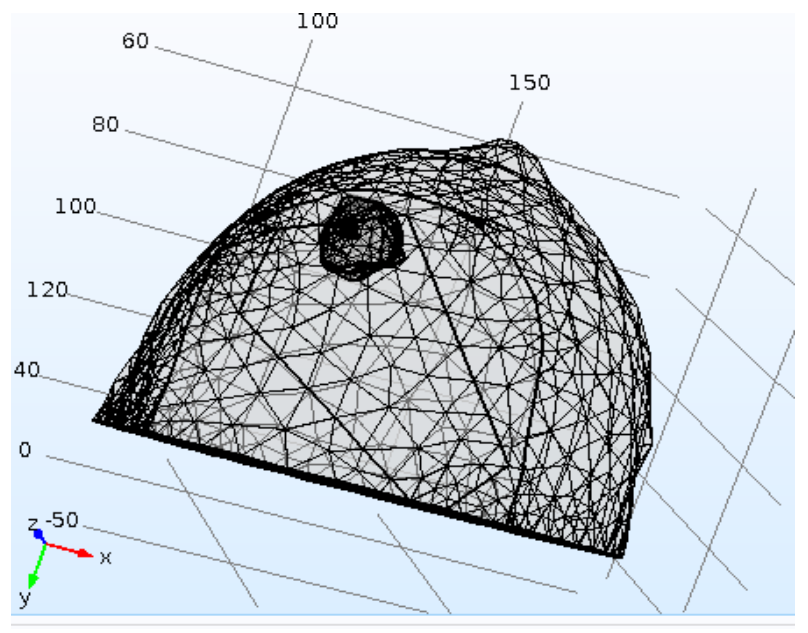

Figure 3: Meshing Refinement in the both the Domains (Breast and the Tumor Region)

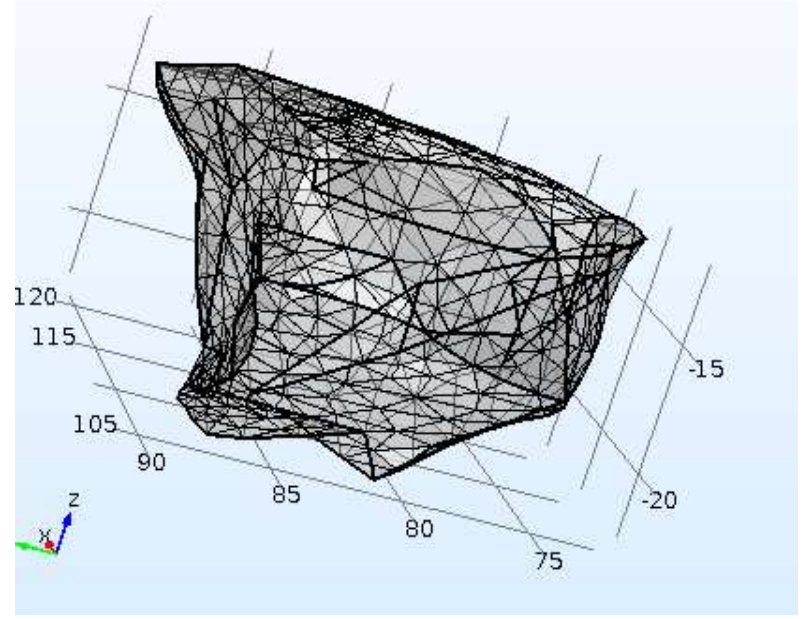

Figure 4: Meshing Refinement of the Cancerous Tumor

Table 3: Physical Properties of Tissue

\begin{tabular}{|l|c|}
\hline \multicolumn{1}{|c|}{ PROPERTIES } & VALUE \\
\hline Heat Capacity & $2348[\mathrm{~J} / \mathrm{kg} . \mathrm{K}]$ \\
\hline Density & $911\left[\mathrm{~kg} / \mathrm{m}^{3}\right]$ \\
\hline Thermal Conductivity & $0.21[\mathrm{~W} / \mathrm{m} . \mathrm{K}]$ \\
\hline Frequency factor & $4.436^{*} 10^{16}[1 / \mathrm{s}]$ \\
\hline Activation energy & $1.3 * 10^{5}[\mathrm{~J} / \mathrm{Mol}]$ \\
\hline
\end{tabular}

Table 4: Physical Properties of Tumor

\begin{tabular}{|l|c|}
\hline \multicolumn{1}{|c|}{ PROPERTIES } & VALUE \\
\hline Heat Capacity & $3700[\mathrm{~J} / \mathrm{kg} . \mathrm{K}]$ \\
\hline Density & $1050\left[\left[\mathrm{~kg} / \mathrm{m}^{3}\right]\right.$ \\
\hline Thermal Conductivity & $0.5[\mathrm{~W} / \mathrm{m} . \mathrm{K}]$ \\
\hline Frequency factor & $9.4 * 10^{104}[1 / \mathrm{s}]$ \\
\hline Activation energy & $660000[\mathrm{~J} / \mathrm{Mol}]$ \\
\hline
\end{tabular}

\section{DOMAIN AND BOUNDARY EQUATIONS}

\section{ELECTROMAGNETICS}

Coaxial cable caring electromagnetic wave is characterized by transverse electromagnetic fields (TEM). Assuming time harmonic fields with complex amplitudes containing the phase information, the appropriate equation is: 


$$
\begin{aligned}
& \mathrm{E}=\mathrm{e}_{\mathrm{r}} \frac{C}{r} \mathrm{e}^{\mathrm{j}(\omega t-\mathrm{kz})} \\
& \mathrm{H}=\mathrm{e}_{\varphi_{\mathrm{Z}}} \frac{C}{\mathrm{e}^{\mathrm{j}(\omega \mathrm{t}-\mathrm{kz})}} \\
& \mathrm{P}_{\mathrm{av}}=\int_{\text {rinner }}^{\text {router }} \operatorname{Re}\left(\frac{1}{2} E * H\right) 2 \pi \mathrm{rdr}=\mathrm{e}_{\mathrm{Z}} \pi \frac{C^{\wedge} 2}{Z} \ln \left(\frac{\text { router }}{\text { rinner }}\right)
\end{aligned}
$$

Where,

\begin{tabular}{|c|l|}
\hline $\mathbf{Z}$ & \multicolumn{1}{|c|}{ Direction of propagation } \\
\hline $\mathrm{r}, \varphi$ and $\mathrm{z}$ & $\begin{array}{l}\text { Cylindrical coordinates centered on } \\
\text { the axis of the coaxial cable }\end{array}$ \\
\hline $\mathrm{P}_{\mathrm{av}}$ & $\begin{array}{l}\text { Time averaged power flow in the } \\
\text { cable. }\end{array}$ \\
\hline $\mathrm{Z}$ & $\begin{array}{l}\text { Wave impedance in the dielectric of } \\
\text { the cable }\end{array}$ \\
\hline rinner and r outer & Dielectric inner and outer radius \\
\hline$\Omega$ & Angular frequency \\
\hline
\end{tabular}

The propagation constant $k$, relates to the wavelength in the medium, $\lambda$ as:

$k=\frac{2 \pi}{\lambda}$

In the tissue, the electric field also has a finite axial component, whereas the magnetic field is purely in the azimuthal direction. Thus, model the antenna using an axisymmetric transverse magnetic (TM) formulation. The wave equation then becomes scalar in $\mathrm{H} \varphi$ :

$$
\nabla *\left(\left(\varepsilon_{\mathrm{r}}-\frac{j \sigma}{\omega \varepsilon_{o}}\right)^{-1} \nabla * \mathrm{H} \varphi\right)-\mu_{\mathrm{r}} k_{\mathrm{o}}^{2} \mathrm{H} \varphi=0
$$

The boundary conditions for the metallic surfaces are:

$$
\mathrm{N} * \mathrm{E}=0
$$

The point is modelled using a port boundary condition with a power level set to $10 \mathrm{~W}$. This is essentially a first order low, reflecting boundary condition with an input field $\mathrm{H} \varphi_{\mathrm{o}}$ :

$$
\mathrm{n} * \sqrt{\varepsilon} E-\sqrt{\mu} \mathrm{H}_{\varphi}=-2 \sqrt{ } \mu \mathrm{H} \varphi_{\mathrm{o}}
$$

Where, $\mathrm{H} \varphi_{\mathrm{o}}=\frac{\sqrt{\frac{P a v Z}{\pi r \ln (\text { router } / \text { rinner })}}}{r}$

Applying this boundary condition to all boundries

\section{HEAT TRANSFER}

The bio heat equation describes the time dependent heat transfer problem as:

$$
\rho \mathrm{C}_{\mathrm{P}} \frac{d T}{d t}+\nabla(-k \nabla \mathrm{T})=\rho_{\mathrm{b}} \mathrm{C}_{\mathrm{b}} \omega_{\mathrm{b}}\left(\mathrm{T}_{\mathrm{b}}-\mathrm{T}\right)+\mathrm{Q}_{\mathrm{met}}+\mathrm{Q}_{\mathrm{ext}}
$$

Where, 


\begin{tabular}{|c|l|}
\hline$k$ & Tissue thermal conductivity $(\mathrm{W} / \mathrm{m} . \mathrm{k})$ \\
\hline$\rho_{\mathrm{b}}$ & Blood density $\left(\mathrm{kg} / \mathrm{m}^{3}\right)$ \\
\hline $\mathrm{C}_{\mathrm{b}}$ & Blood specific heat capacity \\
\hline$\omega_{\mathrm{b}}$ & Blood perfusion rate $(1 / \mathrm{s})$ \\
\hline $\mathrm{T}_{\mathrm{b}}$ & Arterial blood temperature $(\mathrm{K})$ \\
\hline $\mathrm{Q}_{\mathrm{met}}$ & Heat source from metabolism $\left(\mathrm{W} / \mathrm{m}^{3}\right)$ \\
\hline $\mathrm{Q}_{\mathrm{ext}}$ & External heat source $\left(\mathrm{W} / \mathrm{m}^{3}\right)$ \\
\hline
\end{tabular}

The initial temperature $T_{b}$ is applied to all domains. The heat source from the metabolism is neglected in this model. The external heat source is equal to the resistive heat generated by the electromagnetic field:

$$
\mathrm{Q}_{\mathrm{ext}}=1 / 2 \operatorname{Re}[(\sigma-\mathrm{j} \omega \varepsilon) \mathrm{E} . \mathrm{E}]
$$

Table 5: Parameters of Blood

\begin{tabular}{|l|c|}
\hline \multicolumn{1}{|c|}{ PARAMETERS } & VALUE \\
\hline Density of blood & $1000\left[\mathrm{~kg} / \mathrm{m}^{3}\right]$ \\
\hline Heat capacity & $4180[\mathrm{~J} / \mathrm{kg} . \mathrm{K}]$ \\
\hline Blood perfusion rate & $0.0064[1 / \mathrm{s}]$ \\
\hline Arterial blood temperature & $37^{\circ}$ \\
\hline Initial and boundary temperature & $37^{\circ}$ \\
\hline
\end{tabular}

In addition to the heat transfer, the tissue damage integral is also computed. This gives an idea about the degree of tissue injury $\alpha$ during the process, based on the Arrhenius equation:

$$
\frac{d \alpha}{d t}=\mathrm{A} \exp \left(-\frac{d E}{R T}\right)
$$

Where, $\mathrm{A}$ is the frequency factor $(1 / \mathrm{s})$ and De is the activation energy for irreversible damage reaction $(\mathrm{J} / \mathrm{mol})$.

\section{SPECIFIC ABSORPTION RATE DISTRIBUTION (SAR)}

SAR can be defined as the energy absorbed by living tissue when the body is exposed to electromagnetic field at radio-frequency range can be measured by the specific absorption rate. This indicates the absorption power per mass of living tissue or watts per kilogram (W/kg). The heating ability of microwave antenna is studied with the help of SAR distribution. Heat generated by an electric field in living tissue is given by:

$\mathrm{SAR}=\frac{\sigma * E^{\wedge} 2}{\rho}$

Where,

\begin{tabular}{|l|l|}
\hline$\rho$ & Density of tissue $\left(\mathrm{kg} / \mathrm{m}^{3}\right)$ \\
\hline$\sigma$ & Conductivity of tissue $(\mathrm{S} / \mathrm{m})$ \\
\hline $\mathrm{E}$ & Electric field $(\mathrm{V} / \mathrm{m})$ \\
\hline
\end{tabular}

Heat generated by the antenna as SAR can be applied as an external heat source in bio heat. Therefore, bio heat equation can be written as:

$$
\rho \mathrm{C}_{\mathrm{P}} \frac{d T}{d t}+\nabla(-k \nabla \mathrm{T})=\mathrm{h}\left(\mathrm{T}_{\mathrm{b}}-\mathrm{T}\right)+\rho \cdot \mathrm{SAR}
$$

\section{RESULTS}

Figure 5 and Figure 6, shows the temperature distribution for the duration of $10 \mathrm{~min}$. and 20 min., respectively in the tumor, at the frequency range of $2.4 \mathrm{GHz}$. The peak value of the temperature is around the slot and its highest value 
near the microwave antenna slot. Maximum temperature of $52^{\circ} \mathrm{C}$ is attained which is optimum for the treatment of the tumor of microwave induced hyperthermia. Temperature in a tumor model rises to $52^{\circ} \mathrm{C}$ within 10 minutes at power of $3 \mathrm{~W}$ and it is observed after a certain period of time temperature remains constant at the same point. Therefore, the temperature after 20 minutes remains $52^{\circ} \mathrm{C}$. A temperature higher than $52^{\circ} \mathrm{C}$ can be harmful to the body where it may affect the healthy tissues. Temperature distribution on the surface of tumor at three different points during the duration of 10 minutes is shown in Figure 7 and these points are located at random location according to the Figure 17from the tip of the probe. Similarly, Temperature distribution on the surface of tumor at three different points during the duration of 20 minutes is shown in Figure 8. Table 6shows the time required for attaining particular temperature and the power corresponding to it, and represents temperature at a point when the power supply of the antenna is varied from $1 \mathrm{~W}$ to $5 \mathrm{~W}$ and the duration of time which is used for the heating of the tumor are $10 \mathrm{~min}, 20 \mathrm{~min}$, and $30 \mathrm{~min}$, respectively. It is clear from the readings that, the temperature rise in the tumor is seen up to $10 \mathrm{~min}$ and after that, the temperature inside the tumor is constant and does not vary in $20 \& 30$, with an increase in time. The same is seen for the other power supply values that's as we increase the power of the antenna the temperature increase up to 10 minutes and after that the temperature becomes constant. Figure 9 shows the SAR distribution in the breast model. As it can be seen that the sudden peak in the graph shows the sudden increase in the value of SAR, this sudden peak can be seen in the area closer to the tip of the antenna and as the value of SAR is evaluated away from the antenna it come out to be less as which can be observed in the plot. The power of the antenna is kept, such as the there is no effect of electromagnetic wave on the other parts of the body other than the part that is diagnosed that's the tumor region. The figure 11,12,13,14,15,16 shows the current density, total power dissipation, electric displacement field and electric field in the breast and tumor model. The result is computed at the breast model whose volume is $561300 \mathrm{~mm}^{3}$ and the surface area of the breast model is $3600 \mathrm{~mm}^{2}$, whereas the volume of the tumor region is $1734 \mathrm{~mm}^{3}$ and the surface area of the tumor region is taken as $877.7 \mathrm{~mm}^{2}$. The power required and the temperature produced inside the tumor also depends upon the area of the tumor region.

Table 6: Temperature Rise Corresponding to Power and Time

\begin{tabular}{|c|c|c|c|}
\hline \multirow{2}{*}{ POWER (W) } & \multicolumn{3}{|c|}{ TEMPERATURE (max.) } \\
\cline { 2 - 4 } & $\mathbf{1 0} \mathbf{~ m i n}$ & $\mathbf{2 0} \mathbf{~ m i n}$ & $\mathbf{3 0}$ min \\
\hline $1 \mathrm{~W}$ & $43^{\circ} \mathrm{C}$ & $43^{\circ} \mathrm{C}$ & $43^{\circ} \mathrm{C}$ \\
\hline $2 \mathrm{~W}$ & $48^{\circ} \mathrm{C}$ & $48^{\circ} \mathrm{C}$ & $48^{\circ} \mathrm{C}$ \\
\hline $3 \mathrm{~W}$ & $54^{\circ} \mathrm{C}$ & $54^{\circ} \mathrm{C}$ & $54^{\circ} \mathrm{C}$ \\
\hline $4 \mathrm{~W}$ & $60^{\circ} \mathrm{C}$ & $60^{\circ} \mathrm{C}$ & $60^{\circ} \mathrm{C}$ \\
\hline $5 \mathrm{~W}$ & $65^{\circ} \mathrm{C}$ & $65^{\circ} \mathrm{C}$ & $65^{\circ} \mathrm{C}$ \\
\hline
\end{tabular}




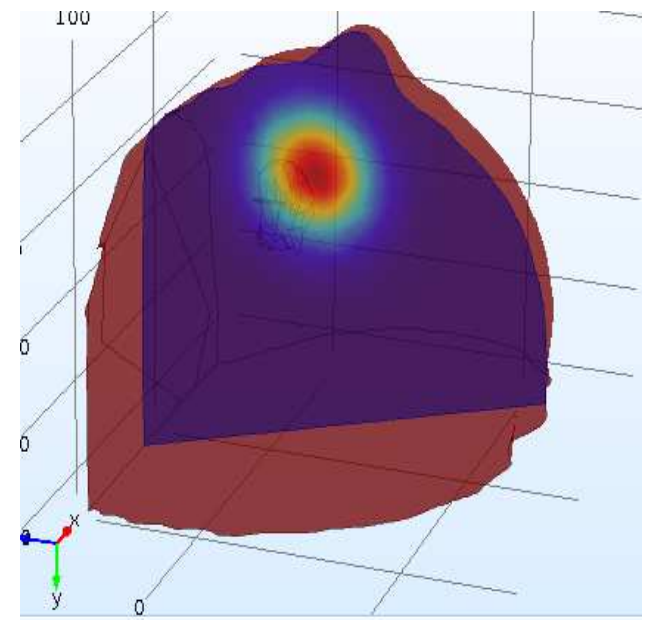

Figure 5: Temperature Distribution in the Breast Model

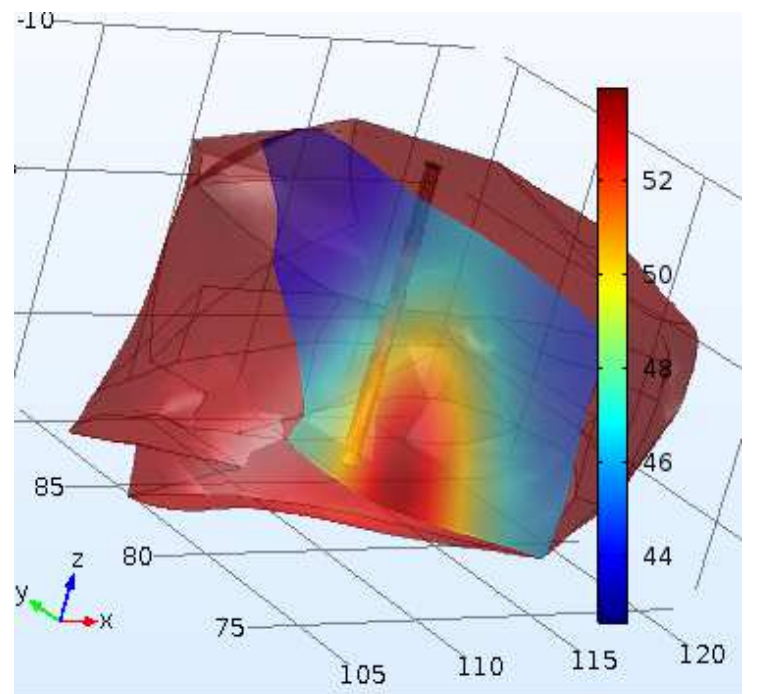

Figure 6: Temperature Distribution in the Tumor Model

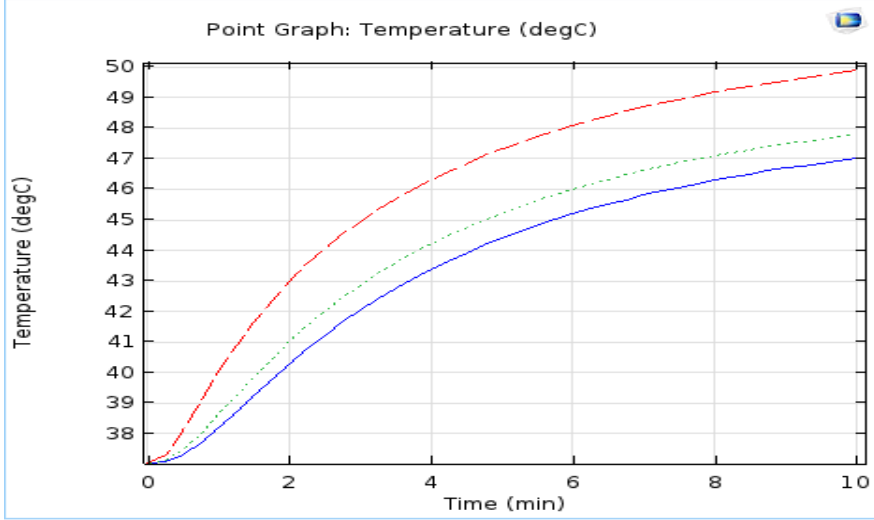

Figure 7: Temperature Distribution on the Surface of Tumor at Three Different Points during the Duration of 10 Minutes 


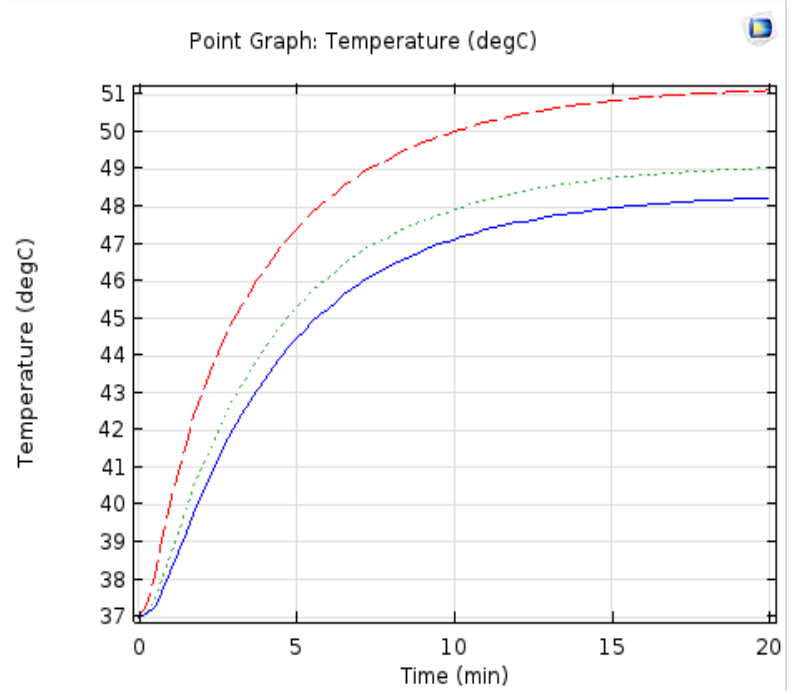

Figure 8: Temperature Distribution in the Surface of Tumor at Three

Different Points during the Duration of 20 Minutes

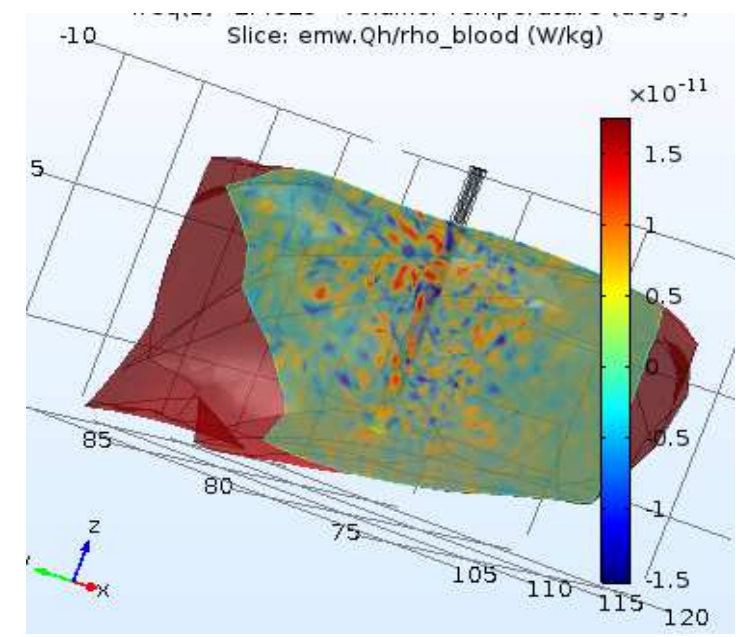

Figure 9: SAR Distribution in the Tumor at the Slice View

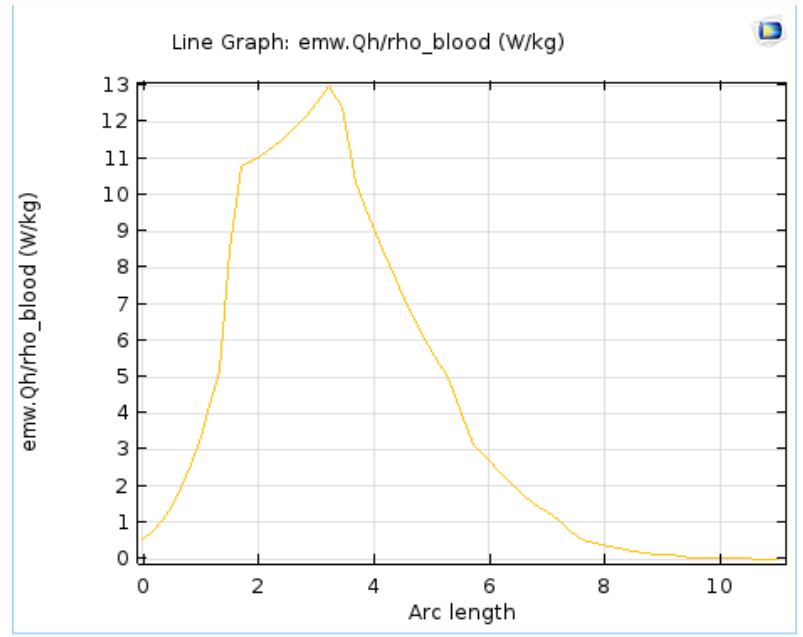

Figure 10: SAR Distribution Plot at the Surface of the Tumor, the Antenna

Inserted Inside the Tumor is at a Frequency of $2.4 \mathrm{GHz}$ 


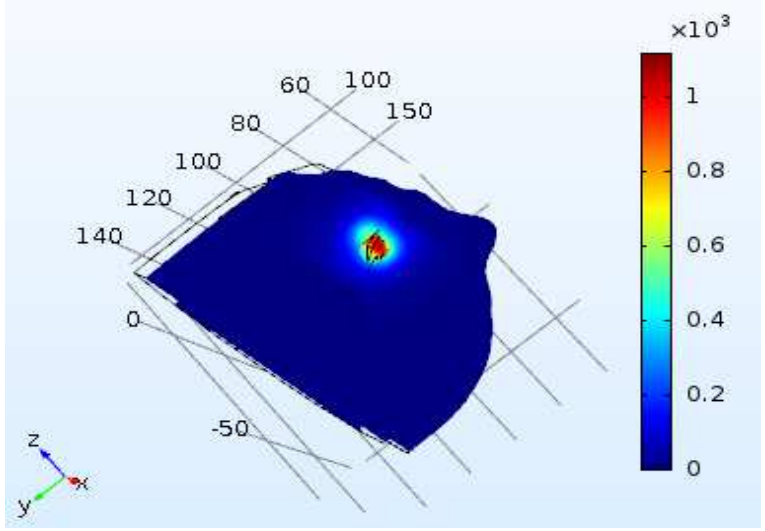

Figure 11: Current Density in the Breast and Tumor Model in the Slice View

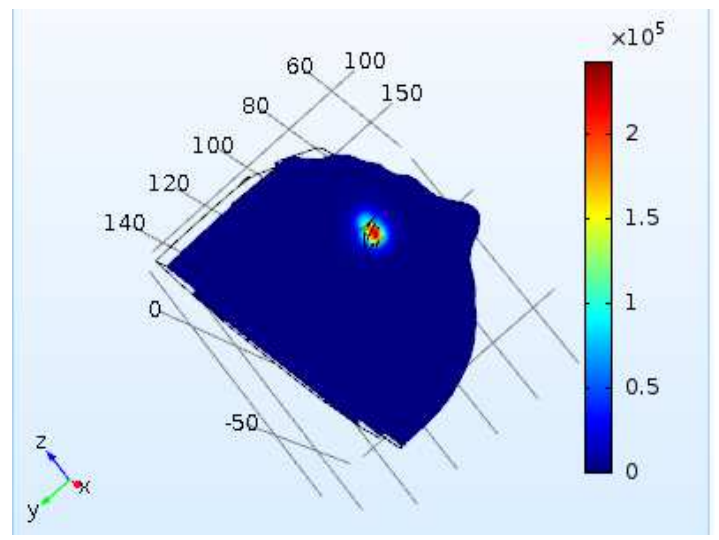

Figure 12: Total Power Dissipation in the Breast and Tumor Model in the Slice View

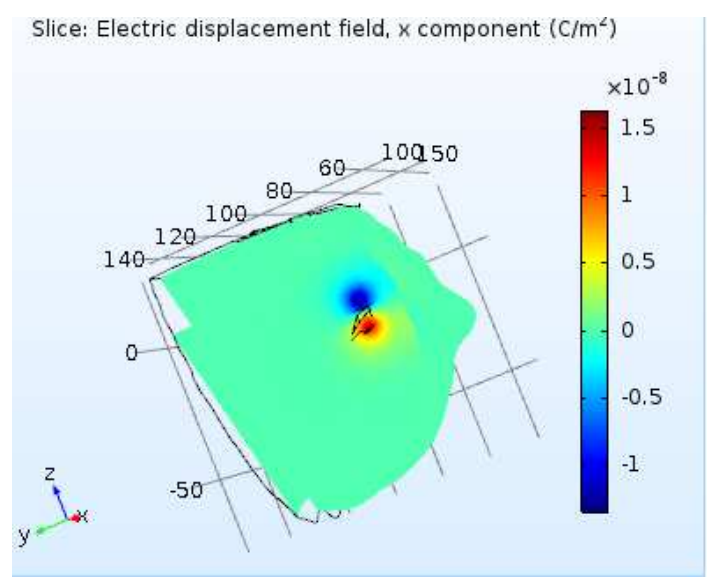

Figure 13: Electric Displacement Filed in the $x$ Direction in the

Breast Tumor Model in the Slice View

To find out the relation between volume of breast and the power required, new term $\alpha$ is introduced. Where $\alpha=$ (volume of breast/power required) $/ 1000$

Table 7: Shows the Value of $\alpha$ at Different Power and Time Required to Attain the Same

\begin{tabular}{|c|c|c|c|c|}
\hline Time (m) & \multicolumn{4}{|c|}{ Temperature $\left({ }^{\circ} \mathbf{C}\right)$} \\
\hline & $1 \mathrm{~W}$ & $2 \mathrm{~W}$ & $3 \mathrm{~W}$ & $4 \mathrm{~W}$ \\
\hline 0 & 37.00 & 37.00 & 37.00 & 37.00 \\
\hline
\end{tabular}


Table 7: contd.,

\begin{tabular}{|c|c|c|c|c|}
\hline 1 & 38.63 & 40.26 & 41.89 & 43.52 \\
\hline 2 & 40.14 & 43.28 & 46.40 & 49.56 \\
\hline 3 & 40.97 & 44.89 & 48.87 & 52.85 \\
\hline 4 & 41.41 & 45.75 & 50.23 & 54.69 \\
\hline 5 & 41.67 & 46.23 & 51.00 & 55.71 \\
\hline 6 & 41.82 & 46.54 & 51.47 & 56.32 \\
\hline 7 & 41.92 & 46.76 & 51.77 & 56.71 \\
\hline 8 & 41.99 & 46.91 & 51.97 & 56.98 \\
\hline 9 & 42.03 & 47.02 & 52.11 & 57.16 \\
\hline 10 & 42.07 & 47.10 & 52.21 & 57.29 \\
\hline$\alpha$ & 11.46 & 5.73 & 3.82 & 2.865 \\
\hline
\end{tabular}

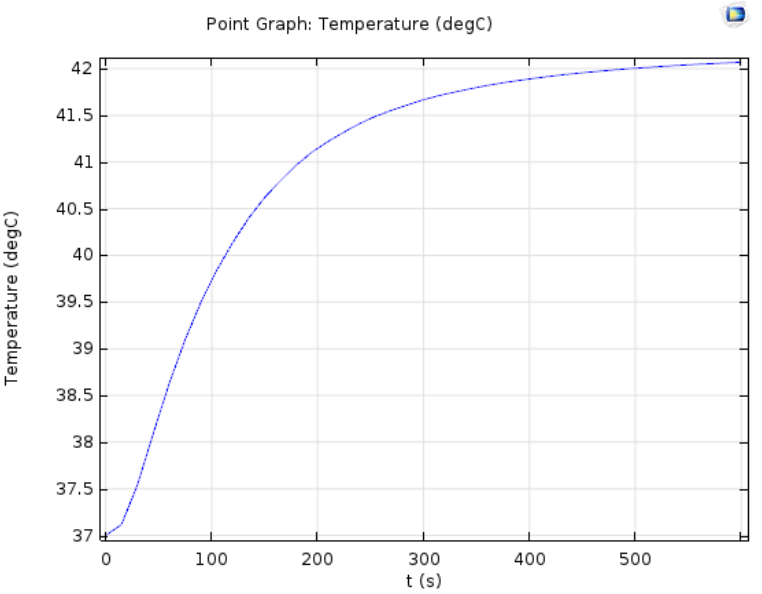

Figure 14: Temperature Rise at Power of 1w

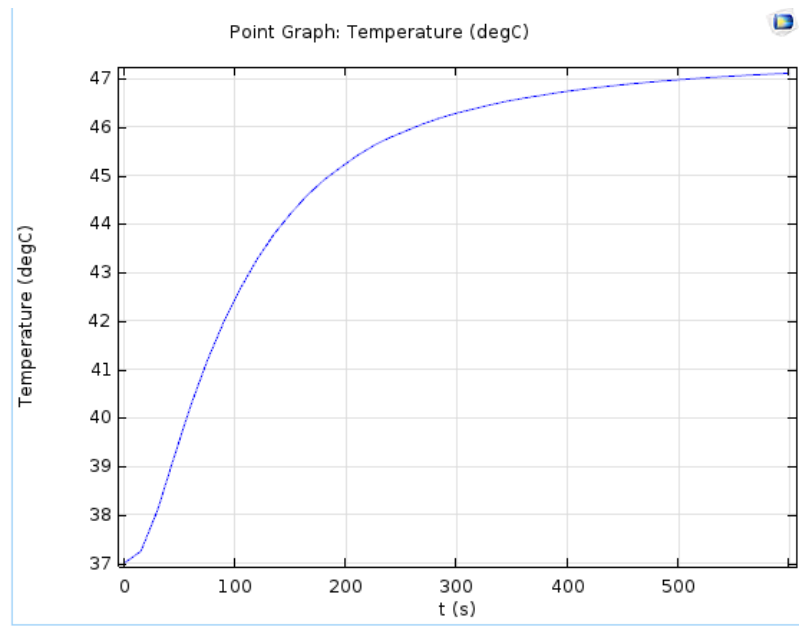

Figure 15: Temperature Rise at Power of 2 w 


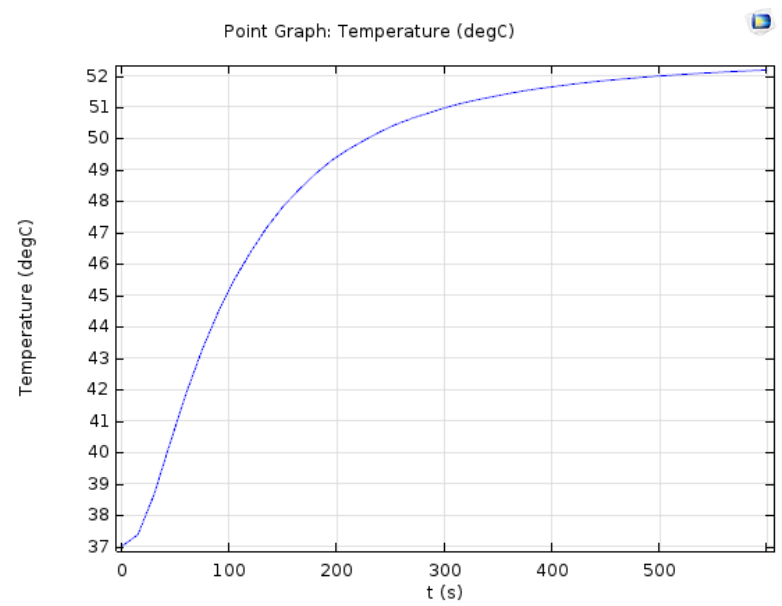

Figure 16: Temperature Rise at Power of 3w

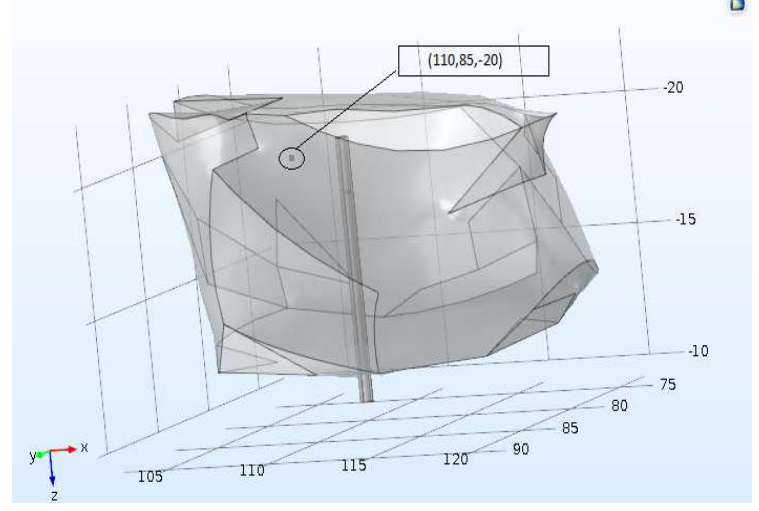

Figure 17: Point in the Tumor where Temprature is Measured at 3W Power

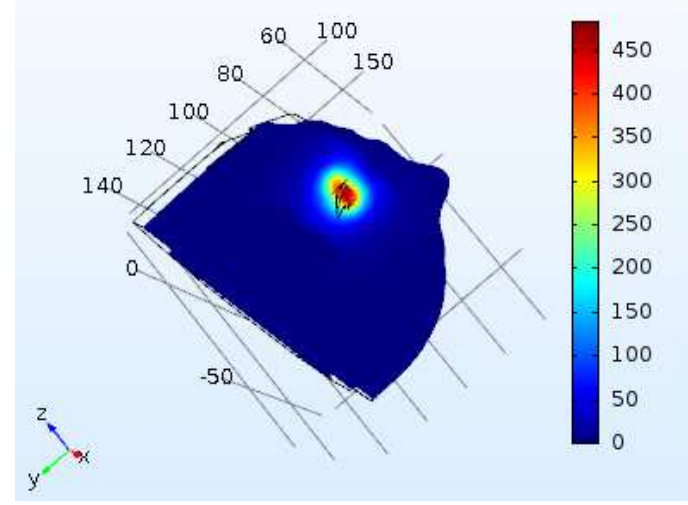

Figure 18: Electric Field in the Breast and Tumor Model in the Slice View

\section{CONCLUSION AND DISCUSSIONS}

The results present a simple methodology of finding best model parameters for the optimal interstitial microwave hyperthermia treatment. A rise in temperature of breast model was observed because of the RF heating.

We are able to see a rise in the temperature in the breast model because of RF heating. The intensity of power of the antenna is kept between $1 \mathrm{~W}$ to $3 \mathrm{~W}$ and the maximum temperature attained by the breast model is between $43^{\circ} \mathrm{Cto} 54^{\circ} \mathrm{C}$ and respectively the time duration under which the temperature increase was studied was 10, 20, 30 minutes respectively. 
The temperature attained is sufficient for eliminating the cancerous cells. The study of the SAR (Specific Absorption Rate) is also done.

Foster, et. al., recommended uniform semi-infinite homogeneous and uniform homogeneous sphere plane of the tissue. SAR calculation and the resulting temperature rise were projected by the finite element solution of the bioheat equation. The effect of the distance between head model and the RF source of SAR distribution is inspected. It was determined that the temperature elevation reached its steady state value after several minutes [14].Abdallah et al. Investigated the SAR effect in the frequency range of $100 \mathrm{MHz}$ to $300 \mathrm{MHz}$ in perpendicular polarized plane waves. The result was computed using the analogy between uniform transmission lines where each layer is replaced with the equivalent transmission line of the same impedance [15].

We are able to study the hyperthermia treatment of cancer by converting the MRI images into the $3 \mathrm{~d}$ model and an attempt has been made to study the relationship between the temperature and its effect on the tumor region. The observation is done at the different points which are $1 \mathrm{~mm}, 2 \mathrm{~mm}$, and $3 \mathrm{~mm}$ away from the tip of the antenna. As studied in literature for the effect of the temperature of the cancerous tissue. The effect of the temperature was studied for the different duration that is for 10,20 , and 30 minutes at the different power supply that is from $1 \mathrm{~W}$ to the $5 \mathrm{~W}$.

Both electromagnetic and ultrasound cylindrical phased array can be used for the hyperthermia treatment of tumor within the breast model. The US designed applicator has a smaller focus size and larger penetration depth than that of the existing hyper collar. Therefore, US applicator is more appropriate for the smaller and the deep located tumor regions, whereas for the larger size tumor hyper collar is preferred and it performs well. Therefore, the further research is required to investigate for the heating profiles.

From the temperature profile distribution, it can be seen that focusing point of the electromagnetic field near the tip of the antenna which is responsible for the hot spot in the temperature distribution in the tissue. The material used for the antenna is dielectric and catheter. The frequency at which the power is supplied to the antenna is taken as $2.45 \mathrm{GHz}$.

Our study will continue with the investigation of non-homogenous heating. For example, a tumor as a sub domain embedded in the normal tissue, or the insertion of ferromagnetic particles in the targeted tissue, in order to better concentrate the radiation energy into it. Also, the study of multiple pin applicator, such as the array of implanted probes investigated for the extension of the conclusions adopted.

\section{REFERENCES}

1. Wust P, Hildebrandt B, Sreenivasa G, et al. Hyperthermia in combined treatment of cancer. The lancet oncology, 2002,3(8): 487-497.

2. Van dee Zee J. Heating the patient: a promising approach? Annals of oncology, 2002, 13(8): 1173-1184.

3. F. Kristian Storm, M.D. Donald L. Morton Localized Hyperthermia in the Treatment of Cancer "CA: A Cancer Journal for Clinicians Volume 33, Issue 1 (2008)

4. F. Kristian Storm, M.D. Donald L. Morton Localized Hyperthermia in the Treatment of Cancer "CA: A Cancer Journal for Clinicians Volume 33, Issue 1 (2008)

5. Riadh W. Y. Habash, Rajeev Bansal, Daniel Krewski, and hafid T. Alhafid. Thermal Therapy, Part 2:Hyperthermia Techniques, Critical reviews in Biomedical Engineering, 34(6):491-542 (2006) 
6. Riadh W. Y. Habash, Rajeev Bansal, Daniel Krewski, andhafid T. Alhafid. Thermal Therapy, Part 2:Hyperthermia Techniques, Critical reviews in Biomedical Engineering, 34(6):491-542 (2006)

7. Silverio Soto Alvarez, Lidia Flor E.Huerta, et al Chracterization of breast cancer radiofrequency ablation assisted with magnetic nanoparticles. Journal of electromagnetic analysis and application, 2016,8, 1-7.

8. http://www.env_health.org/IMG/pdf/23_Breast_cancer_an_ebvironmental_disease_the_case_for_primary_prevention.pdf (retrieved on 09.07.13)

9. Bert Hildebrandt, Peter Wust, Olaf Ahlers, Annette Dieing, GeethaSreenivasa, ThoralfKerner, Roland Felix, Hanno Riess, The cellulr and molecular basis of hyperthermia, Crit. Rev.Oncol./Hematol. 43(2002) 33-56.

10. Robert C. Hansen, Phased Array Antennas, second ed., John Wiley \& Sons Inc., 2009.

11. Piotr gas, study on interstitial microwave hyperthermia with the mult-slot coaxial antenna, Rev. Roum Sci. Techn.Electrotechn. Et Energy., 59,2,p. 215-224, Bucarest,2014

12. David Vrba and Jan Vrba. Novel Applicators for Local Microwave Hyperthermia Based on ZerothOrder Mode Resonator Metamaterial. International Journal of Antennas and PropagationVolume 2014 (2014).ArticleID 631398,7pageshttp://dx.doi.org/10.1155/2014/631398 Comsol Multiphysics, Microwave heating of a cancer tumor.

13. Abdalla A. and Teoh A, "A Multi Layered Model of Human Head Irradiated by Electromagnetic Plane wave of 100MHz300MHz”. 2005

14. Omar A., Bashayreh Q.M and Al-Shamali A.M. "Investigation of the effect of obliquely incident plane wave on a human head at $900 \mathrm{MHz}$ and $1800 \mathrm{MHz} .2010$ 
